\title{
O pewnym typie hasel w XVI-wiecznych słownikach Bartłomieja z Bydgoszczy
}

Słow a k1 u c ze : język polski XVI wieku; leksykografia XVI wieku; słowniki Bartłomieja z Bydgoszczy

Key w ords: Polish language of the 16th century; lexicography of the 16th century; dictionaries by Bartholomew of Bydgoszcz

Celem niniejszego artykułu jest przedstawienie jednego z typów polskich haseł w XVI-wiecznych słownikach bernardyna Bartłomieja z Bydgoszczy. Chodzi o polskie wyrazy i połączenia wyrazowe zapisane w tych leksykonach więcej niż raz.

Łacińsko-polskie słowniki bydgoskiego zakonnika są największymi zbiorami polskiego słownictwa pierwszej połowy XVI wieku (liczącymi łącznie około 15 tysięcy haseł polskich) i przykładami popularnych wówczas w Europie tzw. słowników-encyklopedii. Bartłomiej nie planował ich wydania. Korzystano z nich przede wszystkim w klasztornym studium filozoficznym w Bydgoszczy.

Słowniki z 1532 i 1544 roku różnią się między sobą. Vocabularius ex Calepino, Breviloquo et Mamotrecto recollectus z 1532 roku (dalej: S), o objętości 257 kart, jest wyłącznie rękopiśmienny. Natomiast leksykon z 1544 roku (dalej: R) ma charakter mieszany. Przeważają w nim marginesowe zapiski Bartłomieja - polskie i łacińsko-polskie - na XV-wiecznym druku, liczą- 
cym ponad 600 stron, wokabularza Jana Reuchlina (Vocabularius breviloquus, Argentine 1488). Hasła łacińskie są więc w R albo drukowane (jako część składowa XV-wiecznego wokabularza), albo dopisane ręką zakonnika na marginesach drukowanego dzieła. Z kolei polskie ekwiwalenty haseł łacińskich są zawsze rękopiśmienne ${ }^{1}$.

W obu leksykonach wydzielić można część zasadniczą (główną) oraz słowniczki tematyczne. W części głównej - podzielonej na kilka części znalazły się: rzeczowniki i przymiotniki (nomina), czasowniki (verba) oraz hasła nieodmienne (indeclinabilia).

Nomenklatory dołączone do każdego z leksykonów, odmiennej treści i objętości, umiejscowione są w różnych częściach słowników. W S nomenklatory pojawiły się w środku części zasadniczej (k. 176v - spis dziewięciu chórów anielskich) oraz na końcu leksykonu. Są to nazwy: stopni pokrewieństwa i powinowactwa (De nominibus consanguineorum, De nominibus affinitatis i De cognatione spirituali; k. 250-254), kobiet lekkich obyczajów (Vocabula turpium ac mundanarum mulierum; k. 254-255v) oraz głosów ptaków i zwierząt (Voces animalium et volatilium k. 257). W R dodatkowe słowniczki znalazły się na wyklejkach oprawy druku (przedniej i tylnej) oraz na karcie tytułowej druku. Na karcie tytułowej i na przedniej wyklejce znajdują się terminy gramatyczne (Pro cella predicatoris). Na wyklejce przedniej są też nazwy urzędników. Inne słowniczki dołączone do R to nomenklatory z nazwami: zwierząt, ptaków i ryb (De animalibus, Vocabula volatilium, Vocabula piscium), głosów zwierząt i ptaków (Voces animalium et volatilium), pokrewieństwa (Nomina consanguineorum, Nomina ... affinitatis De cognatis et agnatis i De cognatione spirituals) ${ }^{2}$ oraz chórów anielskich (De hierarchiis angelorum). Jak widać, w S i R powtarzają się nomenklatory z określeniami: głosów zwierząt i ptaków, chórów anielskich i stopni pokrewieństwa.

Słowniki Bartłomieja nie są typowe, co wynika już chociażby z mieszanego charakteru leksykonu z 1544 roku. Dodanie nomenklatorów do S i R nawiązuje do średniowiecznego układu słownictwa według działów. S, chociaż całkowicie rękopiśmienny, nie ma - w części zasadniczej - prostego układu, bo oprócz głównego tekstu łacińsko-polskiego, na większości kart ma dodatkową kolumnę z hasłami łacińsko-polskimi w układzie alfabetycznym oraz

\footnotetext{
1 Najnowszy pełny opis słowników zob. (Jankowiak 2017a, 2017b).

2 Ich opis zob. (Jankowiak, Łuczak 2019).
} 
dodatkowe - rozsiane po marginesach kart (górnym, dolnym, lewym, prawy$\mathrm{m})^{3}$ - albo łacińsko-polskie pary odpowiedników, albo tylko polskie ekwiwalenty wyrazów łacińskich (łacińskiego hasła głównego lub wyrazu z łacińskiej definicji) ze wspomnianych kolumn. Tylko cześć haseł łacińskich w dziełach Bartłomieja uzyskało polskie odpowiedniki, np. na około 22 tysiące haseł łacińskich S ma tylko 20\% haseł z polskimi ekwiwalentami.

Bartłomiej oba leksykony dokładnie datował. Jednak zdaniem pierwszych badaczek dzieł zakonnika, Ireny Kwileckiej i Hanny Popowskiej-Taborskiej (1977: 31-32) data 1532 odnosi się nie do zakończenia całości tego słownika, lecz do ukończenia jego części łacińsko-łacińskiej . A leksykon z datą 1544 bernardyn mógł uzupełniać aż do śmierci, czyli do 1548 roku.

I. Kwilecka i H. Popowska-Taborska udowodniły, że słowniki Bartłomieja powstawały długo, etapami. Zakonnik wracał do zapisanych już kart i dodawał na nich nowe hasła łacińskie lub/i polskie. Według wspomnianych badaczek (np. Kwilecka 1979: 31; Kwilecka, Popowska-Taborska 1977: 31, 43, 54) te powroty do zapełnionych już stron powodowały, że Bartłomiej zaczynał się gubić w swych zapiskach, bo często powtarzał raz już zapisane hasła (łacińskie i/lub polskie) nie tylko w różnych miejscach słownika, lecz także nawet na tej samej stronie danego leksykonu. Chociaż na te powtarzające się zapisy m.in. haseł polskich ${ }^{5}$ wskazywały już ww. badaczki, to jednak dogłębnie kwestii tej nie zbadały, a poczynione przez nie uwagi rozproszone są w różnych publikacjach (np. Kwilecka 1979: 23-36; Kwilecka, Popowska-Taborska 1977: np. 31, 40, 43, 44, 51, 54, 62, 63, 64), podobnie jak i późniejszych badaczek dzieł Bartłomieja - E. Kędelskiej i A. Łuczak (np. Kędelska, Kwilecka, Łuczak 1999: np. 10, 20, 22-23, 48).

Nowa edycja (Kędelska, Kwilecka, Łuczak 1999-2012) - „odwróconej” wersji, tj. polsko-łacińskiej - słowników Bartłomieja z Bydgoszczy ułatwia wskazanie licznych przykładów powtórzeń haseł polskich w tych dziełach.

3 Przy lokalizacjach przykładów stosuję (za nową edycją słowników Bartłomieja z Bydgoszczy) odpowiednio dla tych marginesów skróty: mg, md, ml, mp.

${ }^{4}$ Marginesowe zapisy pojawiały się również po r. 1532, o czym świadczą m.in. hasła przejmowane ze słownika Mymera z wydania z 1541 r. Zob. np. Kędelska, Kwilecka, Łuczak 1999, 27-28; Kędelska 1989: 35.

5 Przez hasła polskie rozumiem zarówno pojedyncze wyrazy, jak i (różnej długości) zestawienia (połączenia wyrazowe, frazy, zwroty itd.). 
Wydanie to obejmuje hasła polskie do leksemu stracenie ${ }^{6}$, czyli ok. 70\% całości polskiego materiału i pokazuje, że powtórzeń haseł polskich jest sporo w obu słownikach. Podzielić je można na kilka grup, z których każda zasługuje na oddzielne zbadanie. W niniejszym artykule celem będzie jedynie ich wskazanie a nie szczegółowa analiza.

Pierwsza z grup powtórzeń haseł polskich gromadzi hasła występujące równocześnie w $\mathrm{S}$ i $\mathrm{R}, \mathrm{w}$ różnych częściach (czyli części zasadniczej i/lub słowniczkach) tych leksykonów, np. aksamit 'aksamit', błądzacy 'obłąkany, szalony', cudzić 'czesać, czyścić, dlugi, filar, grzebiacy, hebel, jadwab 'jedwab', kotwica, letni, morze, mowa, obrona, odrzucić, pleśń, płaszcz, płacić, podbródek, rodzony, siara. Oznacza to, że hasła polskie z S powtarzają się w R. Np. z 450 artykułów hasłowych na literę $N$ z nowej edycji jednocześnie w S i R występuje 141, tj. 31,3\% ${ }^{8}$, np. naczynie, nadaremno, nająć się, namiestnik, namiot, najmniejszy, napiąć, napojony, naruszyć, nasz, natoczyć, nauka, niecierpliwy, niedosłyszacy, nienawiść, nieprędki, niski, nosaty, nowy, nyrka.

Kolejna grupa powtórzeń haseł polskich (wynikająca z budowy słowników) to hasła polskie pojawiające się zarówno w nomenklatorze, jak i części zasadniczej danego słownika. W S hasła znajdowały się w kilku miejscach: w części zasadniczej (w kolumnie głównej, dodatkowej i na marginesach), oraz - w przypadku niektórych grup słownictwa - również w dodatkowych słowniczkach (dalej: SN). Z kolei w R hasła polskie są na marginesach, umieszczone niekoniecznie na poziomie odpowiedniego (tzn. w układzie alfabetycznym) wydrukowanego hasła łacińskiego, ale również rozproszone na karcie (zwłaszcza gdy hasło polskie dopisane jest wraz z łacińskim), oraz w nomenklatorach (dalej: RN). Np.: bliski ( $\mathrm{R} \mathrm{g}_{7} ; \mathrm{R} \mathrm{B}_{7} \mathrm{v} ; \mathrm{R} \mathrm{B}_{6} ; \mathrm{R} \mathrm{b}_{2}$; $\mathrm{R} \mathrm{S}_{4} \mathrm{v}$ i RN II); gamrat 'rozpustnik' (SN 252 i S 154; S 70); miłośnik (SN 252 i S 175v); rod 'ród, pokolenie, rodzina' $\left(\mathrm{R} \mathrm{n}_{6} \mathrm{v} ; \mathrm{R} \mathrm{F}_{1} ; \mathrm{R} \mathrm{G}_{6} ; \mathrm{R} \mathrm{v}_{5} ; \mathrm{R} \mathrm{p}_{6} \mathrm{v} ; \mathrm{R} \mathrm{B}_{5}\right.$; $\mathrm{R} \mathrm{m}_{4} \mathrm{v} ; \mathrm{R} \mathrm{v}_{5}(\mathrm{mg})$ i RN I).

Trzecia grupa przykładów to powtórzenia haseł polskich na tej samej karcie danego słownika (S i R): recto i verso, np. bolaczka (S 12 i S 12v); czarny

${ }^{6}$ Hasła na pozostałe litery przygotowane zostały w ramach grantu NPRH (2012-2018) i wydane zostaną wkrótce przez Instytut Slawistyki Polskiej Akademii Nauk.

$7 \mathrm{Na}$ lit. $N$ odnotowanych jest 495 haseł, jednak $45 \mathrm{z}$ nich to hasła odsyłaczowe, które tu pomijam.

${ }^{8}$ Na lit. $N$ tylko w S odnotowane są 24 hasła $(5,3 \%)$, a tylko w $\mathrm{R}-285$ haseł $(63,3 \%)$. 
las $\left(\mathrm{Ro}_{3}(\mathrm{mp})\right.$ i $\left.\mathrm{Ro}_{3} \mathrm{v}(\mathrm{mg})\right)$; frymarczyć $\left(\mathrm{R} \mathrm{M}_{5} \mathrm{i} \mathrm{R} \mathrm{M}_{5} \mathrm{v}\right)$; łańcuch $\left(\mathrm{R} \mathrm{d}_{5} \mathrm{i} \mathrm{R} \mathrm{d}_{5} \mathrm{v}\right)$; morwa ( $\mathrm{R}_{1}$ i $\left.\mathrm{R} \mathrm{v}_{1} \mathrm{v}\right)$; nakrzywiony ( $\mathrm{R} \mathrm{C}_{6} \mathrm{v}\left(\mathrm{md}\right.$; av. repandus) i $\mathrm{R} \mathrm{C}_{6}(\mathrm{mg})$ ); napis (S 50 i S 50v); obludny (S 69 i S 69v); oddech (S 10 i S 10v); odtaczo$n y\left(\mathrm{R} \mathrm{F}_{3} \mathrm{v}(\mathrm{md})\right.$ i $\left.\mathrm{R} \mathrm{F}_{3}(\mathrm{mp})\right)$; odrzec $\left(\mathrm{R} \mathrm{N}_{6}(\mathrm{mg})\right.$ i $\left.\mathrm{R} \mathrm{N}_{6} \mathrm{v}(\mathrm{mg})\right)$; ogrodzić $\left(\mathrm{R}_{8}\right.$ (mp) i $\mathrm{R} \mathrm{M}_{8} \mathrm{v}(\mathrm{ml})$ ); papirnik (S 23 i S 23v); piosnka ( $\mathrm{R} \mathrm{f}_{1}(\mathrm{mg})$ i $\left.\mathrm{R} \mathrm{f}_{1} \mathrm{v}\right)$; płot $\left(\mathrm{R} \mathrm{F}_{3} \mathrm{i} \mathrm{R} \mathrm{F}_{3} \mathrm{v}\right.$ (mh; av. septum)); przepławić ( $\mathrm{R} \mathrm{V}_{5}$ (mp; av. vado,-are) i $\left.\mathrm{R} \mathrm{V}_{5} \mathrm{v}\right)$; rozeznać ( $\mathrm{R} \mathrm{O}_{3}$ i $\mathrm{R} \mathrm{O}_{3} \mathrm{v}$ ); samostrzelnik ( $\mathrm{S} 13$ i S 13v (av. arcus)); sromota: ze sromota $\left(\mathrm{R}_{7} \mathrm{i} \mathrm{R} \mathrm{p}_{7} \mathrm{v}\right)$. Zapisy pomiędzy kartą recto i verso czasem różnią się grafią, np. przadny kosz: prządny cossh S 21; prządny kossh S 21v; przejć: przeicz $\mathrm{R} \mathrm{V}_{4}$; przeycz $\mathrm{R} \mathrm{V}_{4} \mathrm{v}(\mathrm{mg})$; stok 'źródło, strumień, potok; loch, grota; studnia': Sthok S 69 (mp); Stog S 69v.

Czwarta bardzo liczna grupa przykładów to powtórzenia haseł polskich na tej samej stronie danego słownika. Dzieli się ona na 3 podrupy. Pierwsza z nich obejmuje powtórzenia hasła polskiego w tej samej formie i tym samym znaczeniu (np. ciemię, dłoń, drażnić, karać, kwaśny, modlenie, pilnie, podrzucony, smażyć, spojony). Kolejna podgrupa to powtórzenia hasła polskiego w różnej formie gramatycznej (przypadku, osobie, czasie, rodzaju itd.), np. barwiony: barwiony $\mathrm{R}_{4} \mathrm{v}(\mathrm{ml})$ i barwione $\mathrm{R}_{4} \mathrm{v}(\mathrm{md})$; chwalić: chwalić $\mathrm{R} \mathrm{M}_{6}$ i chwal $\mathrm{R} \mathrm{M}_{6}(\mathrm{mg})$; cień: cień $\mathrm{R} \mathrm{L}_{3}$ i cienie $\mathrm{R} \mathrm{L}_{3}(\mathrm{mp})$; d lużnik: dtużnik $\mathrm{R}_{5}$ i dtużnicy $\mathrm{R}_{5}$; donieść: doniostem $\mathrm{R} \mathrm{O}_{8} \mathrm{v}(\mathrm{ml})$, doniosteś $\mathrm{R}_{8} \mathrm{v}$ $(\mathrm{ml})$, donióst $\mathrm{R} \mathrm{O}_{8} \mathrm{v}(\mathrm{ml})$; frystować: frystować $\mathrm{R}_{2} \mathrm{v}$ i frystowaty $\mathrm{R}_{2} \mathrm{v}(\mathrm{ml}$; av. differ,-ferre); gonić: gonit $\mathrm{R}_{6}(\mathrm{mp})$ i gonić $\mathrm{R}_{6}(\mathrm{mp})$; grzmieć: grzmieć $\mathrm{R} \mathrm{V}_{3} \mathrm{~V}$ i grzmi $\mathrm{R} \mathrm{V}_{3} \mathrm{~V}$ (md); płacić: płacić $\mathrm{R} \mathrm{S}_{6}$; i płacicie $\mathrm{R} \mathrm{S}_{6}(\mathrm{md})$; policzyć: policzyć $\mathrm{R}_{6}(\mathrm{mp})$ i policz $\mathrm{R}_{6}(\mathrm{mp})$; postronny: postronny $\mathrm{R}_{4}$ i postronnych $\mathrm{R} \mathrm{b}_{4}$ (md; av. alienus); przygodność: przygodność $\mathrm{R}_{3}(\mathrm{md})$ i przygodności $\mathrm{R}_{3}$ (md); puklerz: puklerz $\mathrm{R} \mathrm{E}_{6}$ i puklerzem $\mathrm{R}_{6}$ (md); roztworzony: roztworzony $\mathrm{S} 42 \mathrm{v}$ i roztworzone $\mathrm{S} 42 \mathrm{v}$; spodobać się: spodobać się $\mathrm{R}_{6} \mathrm{~V}$ i spodoba sie $\mathrm{R}_{6} \mathrm{v}$.

Następna podgrupa składa się z przykładów haseł polskich, które pojawiają się na tej samej stronie słowników raz samodzielnie, raz w połączeniu wyrazowym, np. burza: burza $\mathrm{R} \mathrm{K}_{1}$ i w burzy $\mathrm{R} \mathrm{K}_{1}$ (mp; av. turbo); chwila: chwila $\mathrm{R} \mathrm{v}_{1}$ i mała chwila $\mathrm{R} \mathrm{v}_{1}$ (md); gniew: gniew $\mathrm{R} \mathrm{M}_{1}$ (md) i zapalony gniewem $\mathrm{R} \mathrm{M}_{1}$ (mg); grzywna: grzywna i poł grzywny $\mathrm{S}$ 87; kołek: kolek $\mathrm{R}_{1} \mathrm{~V}$ i kotki żelazne $\mathrm{R} \mathrm{z}_{1} \mathrm{v}$ (md; av. paxillus); mtocić: młocić $\mathrm{R} \mathrm{V}_{4} \mathrm{v}$ i mtocić cepami $\mathrm{R} \mathrm{V}_{4} \mathrm{v}$; piastunka: piastunka $\mathrm{R} \mathrm{n}_{7} \mathrm{v}$ i piastunka dzieci $\mathrm{R} \mathrm{n}_{7} \mathrm{v}(\mathrm{ml})$; plywać: ptywać $\mathrm{R}_{1} \mathrm{v}$ i plywać na wodzie $\mathrm{R}_{1} \mathrm{v}(\mathrm{ml})$; pobor: pobor $\mathrm{R}_{4} \mathrm{v}(\mathrm{mg})$ i pobor 
dawać $\mathrm{R}_{4} \mathrm{~V}(\mathrm{md})$; poddymać: poddymać $\mathrm{R} \mathrm{V}_{1}$ i poddymać ogień $\mathrm{R}_{1}$; przysięga: przysięga $\mathrm{R}_{3} \mathrm{v}$ i pod przysięga $\mathrm{R}_{3} \mathrm{v}$ (ml; av. attestationes); puszcza: puszcza $\mathrm{R}_{7}$ i głęboka puszcza $\mathrm{R} \mathrm{i}_{7}$ (mp; av. desertum); rękojemstwo: rękojemstwo na czas $\mathrm{R}_{6}$ i rękojemstwo $\mathrm{R}_{6}$; stado: stado $\mathrm{R}_{3}$ i stado koni $\mathrm{R} 1_{3}(\mathrm{mg})$; stajnia: stajnia $\mathrm{R}_{4}$ i wołowa stajnia $\mathrm{R}_{4}(\mathrm{mg})$.

Do grupy powtórzeń z tej samej strony zaliczają się przykłady z kolejnej podgrupy, gromadzącej hasła polskie, które występują za każdym razem w innym połączeniu wyrazowym, np. duch: ducha wywodzenie $\mathrm{R}_{4}$ (md) i ducha wywodzić $\mathrm{R}_{4}$ (md; av. spiratio); dzban: uchaty dzban $\mathrm{R}_{2}(\mathrm{mp}$; av. ansa) i ucho u dzbana $\mathrm{R}_{2}$; gadka: zadanie gadki $\mathrm{R} \mathrm{l}_{1}$ i tajemne gadki $\mathrm{R} \mathrm{1}_{1}$; jatka: jatka mięsna $\mathrm{S} 79$ i rzeźnicza jatka $\mathrm{S} 79$; jezdny: jezdny ziemianin $\mathrm{R} 1_{3}$ i huf jezdny $\mathrm{R}_{3}(\mathrm{mp})$; miernie: miernie działać $\mathrm{R} \mathrm{Q}_{7} \mathrm{v}$ i miernie uczynić $\mathrm{R} \mathrm{Q}_{7} \mathrm{v}$ (md); modła: modła boska S 79v, modta pożyczona S 79v, modła wyższa po Bodze S 79v; nauka: nauka boskich tajemnic 'teologia' $\mathrm{R} \mathrm{J}_{2} \mathrm{v}(\mathrm{mg})$ i nauka bogomowna 'ts.' $\mathrm{R} \mathrm{J} \mathrm{J}_{2} \mathrm{v}(\mathrm{md})$; ociec: krzesny ociec $\mathrm{R} \mathrm{y}_{6} \mathrm{v}$ (md; av. pater) i ociec czeladny $\mathrm{R}_{6} \mathrm{v}(\mathrm{mg})$; pan: młody pan $\mathrm{R}_{3} \mathrm{i}$ pan dziedziczny $\mathrm{R}_{3}(\mathrm{mp})$; piec: chlebowy piec $\mathrm{R}_{1}(\mathrm{mp})$ i kottowy piec $\mathrm{R}_{1}$; prędki: prędki ptak $\mathrm{S} 173$ i prędki ptaszek $\mathrm{S} 173$; rybny: sadzawka rybna $\mathrm{R} \mathrm{p}_{3}(\mathrm{mp})$ i rybne stoly $\mathrm{R} \mathrm{p}_{3}(\mathrm{mp})$; słońce: zaszło słońce $\mathrm{R}_{4} \mathrm{v}$ (ml; av. occidens) $\mathrm{i}$ zachod słońca $\mathrm{R}_{4} \mathrm{v}$.

Jak widać z przytoczonych przykładów, najczęściej powtórzenia dotyczą pojedynczych wyrazów polskich, zwłaszcza rzeczowników i czasowników. Znacznie rzadziej Bartłomiej zapisuje ponownie (szeroko rozumiane) połączenie wyrazowe. Powtórzenia częstsze są w częściach zasadniczych słowników niż w nomenklatorach, co wynika z faktu, że części główne są obszerniejsze. $Z$ powtórzeniem hasła polskiego najczęściej nie wiąże się zmiana znaczenia wyrazu. Zapisane ponownie wyrazy (połączenia wyrazowe) moga różnić się grafią.

Słowniki Bartłomieja, co już podkreślałam, są nietypowe w swej budowie i to częściwo decyduje o powtarzaniu niektórych polskich haseł obok ich odpowiedników łacińskich. Nie wydaje się, by o powtórzeniu danego hasła polskiego decydowało np. jego znaczenie. Analiza semantyczna części z omawianych przykładów (tzn. z grup od 2.-4.) pokazuje, że nie dominuje tutaj jakieś pole tematyczne. Hasła polskie nie układają się w jakieś liczniejsze zespoły tematyczne.

Do najliczebniejszej grupy należą hasła polskie (głównie czasowniki) będące nazwami najróżniejszych czynności (60): konkretnych (29, np. gładzić, 
iść, macać, odpasać 'zdjąć pas', ogranać 'objąć, osiągnąć', plywać, poddymać, podrzucić, przesiewać, przybić 'przymocować, wbić'), abstrakcyjnych (12, np. orędować, przyczynić się 'wstawiać się za kimś, prosić, polecać, zachwalać', przykazać, przystać 'zgodzić się, pozwolić; przyłączyć się do kogoś lub czegoś', rozeznać, tęgie rozmyślanie, zadawać słowa ku rozeznaniu prawdy) lub nazwy mogące dotyczyć obu sfer (19, np.: donieść, dostać, dostapić, naprawić, nasycić, osłabić, opuścić, ochłodzić 'pokrzepić, wzmocnić; orzeźwić', składać 'układać, budować, tworzyć, np. wiersze; konstruować; gromadzić').

Liczna jest też grupa nazw osób (44) z przewagą określeń ludzi wykonujących różne zawody (24), np.: burmistrz, gospodarz 'karczmarz; opiekun przytułku', ociec czeladny, papirnik 'wytwórca papieru', piastunka, robotnik, rzeźnik, samostrzelnik 'wytwórca łuków, kusz; strzelec, łucznik', składacz 'poeta', starosta 'urzędnik, zwierzchnik, przełożony, rządca, namiestnik'.

Zwraca uwagę liczne słownictwo prawnicze (29), np. akt, czas wyzwania, frystować 'odroczyć sprawe sądową', pisarz, prawidło, prawo, przysięga, rękojemstwo, rzecznik 'mówca, adwokat, pośrednik, obrońca', sąd.

Podobna liczba przykładów dotyczy świata zwierząt (27) i roślin (25). W liczebniejszej z grup pojawiły się nazwy gatunków (19, np. bobr, jałowica, jażḋ, krowa, matpa, matpiarz, morska kotka, nietoperz, pstrag) oraz m.in. określenia związane z opieką nad zwierzętami i ich hodowlą (dojna krowa, osypka 'otręby zbożowe, pokarm dla zwierząt', poprag (lub popręg) 'część uprzęży, pas', podwodnik 'koń używany do powinności zwanej podwodą'; sadło 'tłuszcz zwierzęcy', stajnia, świnie koryto). Przykłady dotyczące świata roślin nie są już tak różnorodne, np. brzoza, gałąka, jarzyna, jesion, lebiodka, morski list, okwitnać, orzeszek, owoc, oset.

Mniej liczna (24), ale bardziej zróżnicowana tematycznie, jest grupa przykładów dotyczących jedzenia. Są w niej m.in. nazwy potraw i ich składników (13, np. kiełbasa, krepel 'smażone ciasto, pączek', mąka, okrasa, orzechowy olej), określenia dotyczące przyrządzania potraw (5): pomaszczony, skrobać rzepa abo marchew, smażony, smażyć, wypitwać ryby. Ponadto są tu nazwy naczyń i innych przedmiotów potrzebnych do przygotowywania i spożywania jedzenia (11, np. cyblik 'naczynie do picia dla dzieci', dzban, flaszka, kiella 'naczynie lub łyżka kuchenna', ognisko, panewka 'naczynie kuchenne', piec, skopiec 'naczynie', kredencować 'usługiwać przy stole, próbować i podawać potrawy'). 
Kolejna grupa to określenia różnych zachowań (22). Są to m.in.: drażnić 'dokuczać, irytować, prowokować', łajać, męczenie, oszukanie, otrzec się 'odrzec się, wyrzec', podbić 'poskromić, ujarzmić, pokonać', poddać się, soczyć 'spotwarzać, oskarżać'.

Pozostałe - nieco większe grupy - liczą po mniej niż 20 przykładów. Są to m.in. nazwy dotyczące: religii (17, np. cnota, duch, duchowny, modła, opatrzność), budownictwa (16, np. balka 'belka, strop', gont, kiella 'kielnia murarska', kołek, rynna wodna), wyposażenia domu (14, np. domowe graty, obrus, pościel, ręcznik, rucho 'szata; przykrycie; pościel; zasłona') oraz anatomii człowieka (12, np.: brew, jelito, kość, pięta, stopa).

Kolejne grupy mają po 10 i mniej przykładów. Jest to np. leksyka związaną z chorobami (10, np. bolaczka, blizna, zakażona krew) oraz handlem (10, np. frymarczyć 'handlować', kupia 'kupiectwo, handel; towar; odkupić).

Podsumowanie. Hasła polskie powtarzające się w XVI-wiecznych słownikach Bartłomieja z Bydgoszczy są liczne i różnorodne. Jest ich na tyle dużo, że warto przyjrzeć się każdej z grup oddzielnie, co będzie przedmiotem moich kolejnych opracowań.

Część powtórzeń haseł polskich w dziełach Bartłomieja wynika ze specyfiki leksykonów, (długiego) czasu i sposobu ich tworzenia. Zakonnik od lat 30. XVI w. do swojej śmierci w 1548 r. uzupełniał swe dzieła. Praca ta przebiegała z przerwami, bo Bartłomiej musiał pracę leksykograficzną łączyć z obowiązkami zakonnymi.

Najliczniejsza grupa powtórzeń, tzn. powtórzenia haseł z S w słowniku z 1544 roku, są wynikiem celowego działania leksykografa. Podobnie wyjaśnić można fakt pojawiania się tych samych przykładów z niektórych zespołów tematycznych (np. terminy gramatyczne, nazwy głosów zwierząt czy określenia pokrewieństwa) zarówno w części zasadniczej, jak i słowniczkach tematycznych dołączonych do S i R.

Interpretacja powtórzeń haseł polskich pojawiających się w bliskiej odległości, czyli na tej samej karcie lub na tej samej stronie, jest bardziej skomplikowana. Wcześniejsze badaczki nazywały je jednoznacznie pomyłkami Bartłomieja spowodowanymi m.in. długim czasem powstawania słowników, korzystania przez bernardyna z różnych źródeł i gubienia się zakonnika w ol- 
brzymim materiale łacińsko-polskim (Kwilecka, Popowska-Taborska 1977). Jednak grupa powtórzeń na tej samej karcie czy stronie słownika nie jest tak jednorodna, by można je było interpretować wyłącznie jako pomyłki. Kiedy powtórzenie hasła polskiego łączy się ze zmianą jego formy gramatycznej lub użyciem w połączeniu wyrazowym, to mamy do czynienia $\mathrm{z}$ - może nieuporządkowanym, ale jednak - wzbogacaniem leksyki słownika: wskazaniem różnych kontekstów użycia hasła polskiego lub wprowadzaniem przykładów jego odmiany.

Najtrudniej wyjaśnić przyczyny powtarzania się hasła polskiego w różnych częściach (tzn. na różnych marginesach) na tej samej stronie słownika. Niewątpliwie czytając po przerwie tekst łaciński, Bartłomiej mógł, nie zaglądając już do wcześniejszych polskich zapisków, powtórzyć przez pomyłkę ten sam polski wyraz lub połączenie wyrazowe. $Z$ kolei dany wyraz łaciński mógł nasunąć zakonnikowi skojarzenie z zapisanym już raz polskim hasłem, co wynika z uboższej wówczas (niż łacińska) polskiej synonimiki. Jednak znaczna grupa powtarzających się w bliskiej odległości (w tym samym znaczeniu, z tym samym odpowiednikiem łacińskim) haseł polskich każe zastanowić się w przyszłości (po dokładnym zbadaniu tych przykładów) również nad inną interpretacją tych powtórzeń, być może jako swoistej metody leksykograficznej Bartłomieja.

Po niniejszej wstępnej analizie powtarzających się haseł polskich w XVI-wiecznych słownikach Bartłomieja z Bydgoszczy pewne wydaje się jedynie, że o powtórzeniu hasła polskiego nie decyduje jego znaczenie, budowa czy przynależność do danej części mowy.

\section{Bibliografia}

JANKowiaK L. A., 2017a, Przypomnienie słowników Bartłomieja z Bydgoszczy z lat 1532 i 1544, Studia Językoznawcze. Synchroniczne i diachroniczne aspekty badań polszczyzny 16, s. 107-133, [on-line:] DOI: 10.18276/sj.2017.16-07| 107-133.

JANkowiaK L. A., 2017b, Słowniki Bartłomieja z Bydgoszczy (1532 i 1544). Stan badań i perspektywy badawcze, Poznańskie Studia Polonistyczne. Seria Językoznawcza vol. 24 (44), nr 1, s. 13-26, [on-line:] DOI: 10.14746/pspsj.2017.24.1.1.

JANKOWIAK L.A., 2019, Z warsztatu leksykograficznego Bartłomieja z Bydgoszczy. Powtórzenia haseł [w druku]. 
JANKOWIAK L.A., ŁUCZAK A., 2019, Miejsce nazw związanych z rodziną w słownikach Bartłomieja z Bydgoszczy (1532 i 1544) - uwagi wstępne, w: L. Mariak (red.), Wspótczesny i dawny obraz rodziny w języku, Szczecin: Wydawnictwo Naukowe Uniwersytetu Szczecińskiego, s. 87-105.

KęDELSKa E., 1989, Pierwsze drukowane słowniki łacińsko-polskie jako źródło Bartłomieja z Bydgoszczy, Studia z Filologii Polskiej i Stowiańskiej 25, s. 31-45.

KęDelska E., Kwilecka I., Łuczak A., 1999-2012, Stownik Barttomieja z Bydgoszczy. Wersja polsko-łacińska, cz. 1-5. Warszawa: SOW (wersji elektroniczna w Repozytorium Cyfrowym Instytutów Naukowych).

Kwilecka I., Popowska-Taborska H., 1977, Barttomiej z Bydgoszczy leksykograf polski pierwszej połowy XVI w., Wrocław-Gdańsk: Zakład Narodowy imienia Ossolińskich, Wydawnictwo PAN.

KwILECKa I., 1979, Warsztat pisarski Bartłomieja z Bydgoszczy, w: Barttomiej z Bydgoszczy i jego dzieło, Warszawa-Poznań, s. 23-36.

\section{About a certain type of entries in the 16th century dictionaries by Bartholomew of Bydgoszcz}

( su m mary)

The article presents one of the types of the Polish entries in the 16th century Latin-Polish dictionaries by Bartholomew of Bydgoszcz, i.e. the Polish words and word combinations included in these lexicons more than once. One can distinguish 4 major types of the recurring Polish entries: 1) entries occurring simultaneously in the dictionary of 1532 and of 1544; 2) entries recurring in the major parts of the dictionaries and in the enclosed thematic dictionaries, 3) entries recurring on the same sheet of the dictionary (recto side and verso side), 4) entries recurring on the same page of the dictionary. The recurrences of the Polish entries have various reasons, including the dictionary structures, using a variety of sources, a long period of time over which the dictionaries were created and Bartholomew's mistakes. 